\section{Life in the NIH Intramural Research Program: Great Colleagues, Grand Possibilities, Cutting Edge Technology}

A combination of creative atmosphere, great colleagues, and reliable science support has made the $\mathrm{NIH}$ Intramural Research Program a singularly superb place to do science. This is true for me and for many of the 1,230 principal investigators who have made their research homes on $\mathrm{NIH}$ campuses in Maryland, North Carolina, Montana, and Arizona. We tackle challenging research questions, often with interactive teams incorporating expertise that spans the breadth of biomedicine, from molecular structure to clinical trials in behavioral medicine.

In this article -- and others that will appear in this space over the next few years -- my colleagues and I hope to show you why the Intramural Program is so extraordinary. In fact, for people whose top priority is doing outstanding biomedical research, $\mathrm{NIH}$ might offer the most creative, stimulating, and supportive environment that is available anywhere today.

The Intramural Research Program of the National Institutes of Health traces its roots to the nation's first governmentsupported biomedical research-a single-room laboratory on Staten Island, opened in 1887. From the start, our research has been driven by the most urgent biomedical and public health issues, including contagious and chronic diseases that threatened the well being of the nation.

For me personally, as for most intramural scientists, it is these urgent questions and challenges that continue to drive our research. Repeatedly over the years, NIH scientists have led the way in finding answers -- or basic approaches - to difficult questions. Groundbreaking work in the Intramural programs includes cracking the genetic code; developing the first techniques for culturing human cells; creating the first artificial heart valve; pioneering the use of lithium to treat bipolar disorder; isolating the HIV virus and the first drug known to suppress its growth; and developing a vaccine for Haemophilus influenzae type $B$, a leading cause of childhood meningitis.

Every day exciting results continue to emerge from Intramural labs. Our annual Research Festival (http://researchfestival.nih. gov/) this month features new discoveries in membrane protein structure, gene discovery, vaccine development, proteomics, obesity, and the use of nitrite to treat vasoconstrictive disorders-among hundreds of other advances. My own research program in the National Cancer Institute has focused on the isolation, characterization, and circumvention of multidrug resistance genes expressed by cancer cells to thwart many types of chemotherapy.

When I visit labs around the world to discuss my research, I often draw raised eyebrows with my enthusiasm for the foment of $\mathrm{NIH}$ discovery and the creative, supportive government institution that produces it. It could be this bias that has made the intramural program - often called "the jewel in the crown of the federal government" -- something of a hidden gem.

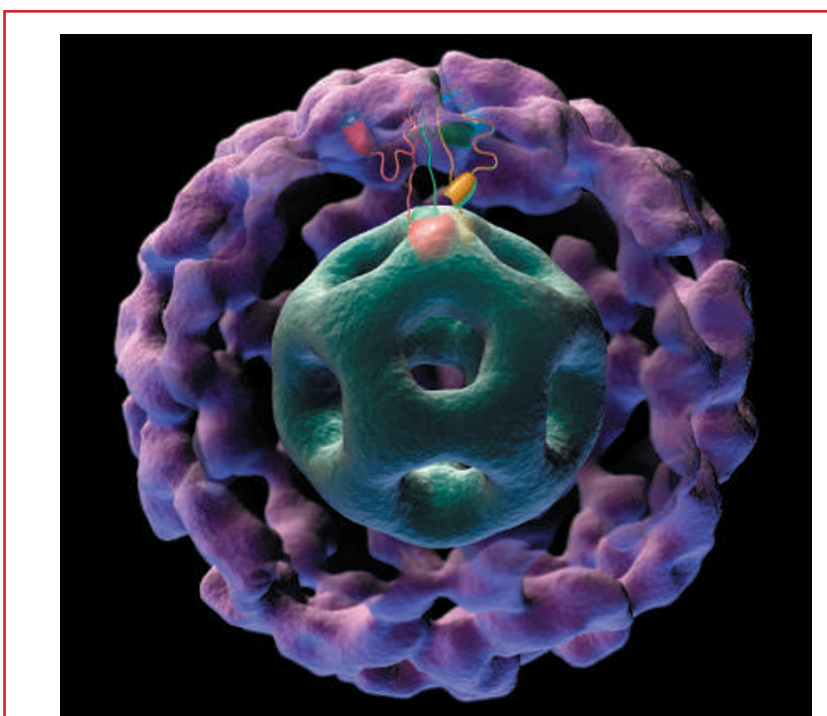

Molecular architecture of the multienzyme pyruvate dehydrogenase complex analyzed using three-dimensional cyroelectron microscopy. From the work of Jacqueline Milne and Sriram Subramaniam at the National Cancer Institute, $\mathrm{NIH}$

But people who know the intramural program well and who work here tell me that some aspects of the intramural environment provide an unusually stimulating atmosphere for them and the perfect place to build a research career:

-Stable lab support that is contingent on rigorous site visit reviews rather than prospective grant proposals

-The world's largest clinical research hospital in close physical and intellectual proximity to basic research labs

-Access to a critical mass of expertise in a vast range of areas- and enthusiastic collaboration

-State-of-the-art instrumentation and shared technical core labs

-A climate of intellectual tolerance and scientific freedom

-Broad acceptance of the value of risk-taking in the pursuit of the most rewarding research targets

-The intellectual pleasure of research mentoring of our 5,000 trainees

-The opportunity to make intellectual and public health contributions that are not dictated or valued by commercial impact

I have emphasized here the Intramural research mission. But the factors that make $\mathrm{NIH}$ an excellent place for a research career also make it an ideal spot for our two other missions research training for students and postdocs, and the transfer of technology from our labs and clinics to commercial developers. We hope you will watch this space in the months ahead to learn more about these and other aspects of life in the Intramural Research Program at $\mathrm{NIH}$.

Michael Gottesman, M.D.

Deputy Director for Intramural Research

National Institutes of Health 

application instructions see http://www.usajobs.opm.gov/. Search by Vacancy Announcements NIA-05-66442A and B. For info contact Pat Boyce at 410-558-8032. Applications must be received by November 15, 2005.

\section{Health Scientist Administrator Opportunity for Specialist in Behavioral/Population Genetics!}

BSR is seeking staff with expertise in behavioral/population genetics, or strong genetics/ social science research. BSR is an Extramural Research Program, with a strong interdisciplinary focus, that supports basic research and training in a wide variety of disciplines.

The National Advisory Council on Aging, workgroup on genetics (May 2004), advised that BSR continue to expand the integration of genetics with behavioral and social sciences. The successful candidate will take the lead in implementing their recommendations, including:

- Developing criteria for priority setting within the growing genetics and genomics portfolio

- Linking social and behavioral sciences to genomics activity at the NIH and elsewhere
- Exploring specific topics that might be particularly tractable

- Assembling a small expert group to discuss priority areas that focus on bringing together social sciences and genetics, to better focus pursuits

- Supporting interdisciplinary training programs for behavioral geneticists

The successful candidate will demonstrate independent research experience plus progressive responsibility in research program administration. This position will challenge someone with vision, skills and insight to take a growing program to new heights. Responsibilities of this position include:

- Providing scientific leadership, defining short-range and longterm goals for research integrating genetics and the socialbehavioral sciences in studies on aging

- Developing areas of scientific research emphasis by inviting grant applications

- Identifying research areas warranting increased or decreased funding emphasis

- Serving as project officer on wide-ranging and cutting-edge behavioral research studies

- Serving as Program spokesperson with the scientific community, the Congress, and other Federal agencies

\section{Health Scientist Administrator Opportunity for Specialist in Biodemography!}

BSR is seeking staff with expertise in population and biological sciences to plan and develop an interdisciplinary portfolio of research and training grants, drawing on the intersection of population sciences, genetics, and evolutionary theories of aging. Experience with biomarkers, clinical physiology, physical anthropology, and performance measures in large-scale longitudinal studies and surveys is a plus. Candidates should have doctorate level training in the areas specified, independent research experience, and progressive responsibilities in research program administration. This position will challenge someone with skill, vision and insight to take a growing program to new heights. Responsibilities of this position include:

- Providing scientific leadership, defining short-range and long-term goals for social-behavioral sciences research in studies on aging

- Developing areas of research emphasis by inviting grant applications from the scientific community

- Identifying research areas warranting increased or decreased funding emphasis

- Serving as project officer on wide-ranging cutting-edge behavioral research studies on aging

- Serving as spokesperson for agency programs in dealing with the scientific community, the Congress, and other Federal agencies

\section{The NIH Director's Wednesday Afternoon Lecture Series}

Biomedical scientists around the world are invited to join us online to hear leading investigators present their latest results to the NIH Intramural Research community. Lectures may be viewed live at 3:00 p.m., EST (20:00 GMT) on Wednesdays, from September through June. Live webcasts can be viewed under "Today's Events" at: <http://videocast.nih.gov/>

The current schedule of lectures is available at: $<$ http://www 1 . od.nih.gov/wals/schedule.htm>

Upcoming Lectures:

-October 5: Margarita Alegria, Cambridge Hospital, Matching Services to Needs: The Importance of Health Services Research for Reducing Disparities

-October 12: Daniel Weinberger, NIMH, NIH, Complex Genetics in the Human Brain: Lessons from COMT

-October 26: Carolyn Bertozzi, UC Berkely and HHMI, Chemistry in Living Systems: New Tools for Probing the Glycome

The lecture series has archived more than 240 lectures since 1998. Archived lectures can be viewed under "Wednesday Afternoon Lectures" at: $<$ http://videocast.nih.gov/PastEvents. asp>

\section{NINH

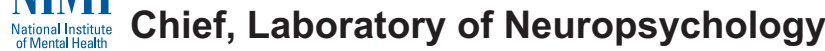

The Laboratory of Neuropsychology (LN) of the NIMH seeks a highly accomplished senior investigator conducting cognitive neuroscience research in nonhuman primates to head an active, ongoing program in this area. The position comes with complementary budget and staff. The strong scientific environment and outstanding resources at NIMH for carrying out such a program make this a unique opportunity for a high-achieving cognitive neuroscientist. The position also offers unparalleled opportunities for interdisciplinary collaboration with scientists throughout the NIH. The successful candidate will be expected to strengthen the current program.

Applicants should have: a Ph.D. and/or M.D. degree; broad experience as an independent investigator applying the techniques of neuropsychology, functional neuroanatomy, behavioral neuroimaging, behavioral electrophysiology, and/or neuropsychopharmacology to research with nonhuman primates; international recognition for studies in one or more of these disciplines; and experience in administering a neuroscience research program.

Salary is commensurate with experience and accomplishments, and a full Civil Service package of benefits (including retirement, health, life, and long-term care insurance, as well as a Thrift Savings Plan, etc.) is available. NIMH is a major research component of the National Institutes of Health and the Department of Health and Human Services, which have nationwide responsibility for improving the health and well being of all Americans. Interested applicants should send curriculum vitae, bibliography, statement of research interests, accomplishments, and goals, together with six letters of reference to: Leslie Ungerleider, Chair, Search Committee for Chief of LN, Bldg. 10, Rm. 4C104, NIH, Bethesda, MD 20892-1366; or email to ungerlel@mail.nih.gov. Application deadline: November 20, 2005. 


\section{Staff Scientist in Molecular Regulation of Cytochrome P450s Research Triangle Park, North Carolina}

The Laboratory of Pharmacology and Chemistry at the National Institute of Environmental Health Sciences is recruiting a staff scientist in support of the Human Metabolism Group headed by Dr. Joyce Goldstein. The recruit will be responsible for individual research and collaborative efforts involving some oversight of the molecular biology and genetics efforts by the group. In particular, the incumbent will focus efforts on generating clones of regulatory regions in appropriate vectors for studies in cell culture models and genetically modified mice to investigate the mechanisms through which drugs, hormones, physiological stimuli regulate CYP genes through receptors, regulatory elements and transcription factors. Current major projects include: regulation of human and murine $\mathrm{CYP} 2 \mathrm{C}$ genes by drugs, hormones, and physiological changes via elements within promoter regions which bind nuclear receptors and transcription factors such as CAR, PXR, HNF4 and coregulators. The successful candidate is expected to work with minimal guidance, carry the research to publishable stages and work on these and other projects as defined by the group leader.

Minimum qualifications include a doctoral degree, successful completion of postdoctoral training, strong publication record and experience in biochemistry and molecular biology, emphasizing molecular techniques involved in studying gene regulation, such as construction and use of luciferase-promoter constructs for use in cell models and murine models, expression vectors for nuclear receptors, construction of clones containing large complex regulatory regions, and use of multi-component plasmid vectors. Specific familiarity with cytochrome P450 regulation by nuclear receptors, antioxidant elements and background in protein chemistry related to identification of corepressors and coactivators of receptors (e.g. DNA chromatography, ChIP assays, yeast-two hybrid assays, GST pulldown) as evidenced by publication record is desirable.

For additional information, contact Dr. Joyce Goldstein at 919-541-4495 or goldste1@niehs.nih.gov. For additional information concerning the research projects and publications of the Human Metabolism Group, visit the following website: http://dir. niehs.nih.gov/dirlpc/. Applications from women and minorities are particularly encouraged. To apply, submit a curriculum vitae, bibliography, references, brief statement of research interests and arrange for three letters of recommendation to be sent by November 15, 2005, to the following address. Applications received after that date will be considered as needed:

Ms. Lisa Rogers (DIR05-09), National Institutes of Health, National Institute of Environmental Health Sciences, P.O. Box 12233, Maildrop, A2-06, 111 Alexander Drive, Room A208, Research Triangle Park, NC 27709, E-mail: dir-appls@niehs. nih.gov

\section{ANEHS \\ thine-itus \\ Investigating Transcriptional Responses to the Environment Research Triangle Park, North Carolina}

Our laboratory's goal is to elucidate the dynamic interplay between signals from the extracellular environment and chromatin architecture, and to probe how chromatin structure and epigenetics influence gene activity. Although it has been known for many years that the compaction of DNA into chromatin can occlude protein binding sites and gene promoters, the ways in which the cellular machinery manipulates chromatin structure to influence gene expression remain poorly understood. A primary aim of our research is to address two key questions in this field, namely: (i) How do histone modifications and nucleosome remodeling affect Pol II initiation and elongation through a gene? (ii) What are the structural rearrangements that take place in a nucleosome to allow Pol II to access the information within the wrapped DNA?

Understanding the transcriptional response to specific extracellular signals is crucial for a full appreciation of many biological and pathological events involving gene-environment interactions. We are undertaking a broad RNAi screen in Drosophila cell culture to identify proteins that are involved in gene regulation and modifications of chromatin structure during the stress response, accompanied by extensive in vivo and in vitro characterization of the critical factors (e.g. Adelman, et al., Mol Cell, 2005). These studies will take advantage of the availability of cutting-edge Microarray, protein expression, structural biology and Mass Spectrometry facilities at the NIEHS, as well as the novel, single-molecule biophysical techniques that are being developed in our laboratory (Adelman, et al., Mol Cell, 2004; Adelman, et al., PNAS, 2002).

Applicants must possess a Ph.D. in Biochemistry, Biophysics or molecular biology and have less than five years of relevant postdoctoral experience. Salary will be commensurate with experience. Applications should be received no later than December 7, 2005. For consideration, send cover letter, curriculum vitae including list of publications, and the names/phone numbers/email addresses of three people who could provide letters of reference to: Dr. Karen Adelman, Laboratory of Molecular Carcinogenesis, National Institute of Environmental Health Sciences, Room D454A, Mail Drop D4-02, 111 Alexander Drive, Research Triangle Park, NC 27709, FAX: 919-541-0146, Email: adelmank@niehs.nih.gov, http://dir.niehs. ih.gov/dirlmc/transcript.htm

\section{\& NuEHS \\ Tenure-Track Investigator Cellular and Molecular Biologist Research Triangle Park, North Carolina}

With nation-wide responsibility for improving the health and well being of all Americans, The Department of Health and Human Services oversees the biomedical research programs of the National Institutes of Health. The National Institute of Environmental Health Sciences, a major research component of the National Institutes of Health (NIH) and the Department of Health and Human (HHS) is recruiting a Tenure -Track Investigator-Cellular and Molecular Biologist with research strengths in metabolic nuclear receptors such as peroxisome proliferator-activated receptors (PPARS) and their fundamental mechanisms of action in relation to diseases such as obesity. Research expertise in signaling, transcriptional/translational regulatory mechanisms and molecular imaging is desirable. Model systems need not be restricted to mammals. Applicants should have a Ph.D., MD/Ph.D., MD or equivalent with 3 years of postdoctoral research experience and a strong publication record. The successful applicant will be expected to establish a high-quality independent research program in the area of PPARS or other metabolic nuclear receptors within a basic science research Branch having diverse interests in molecular signaling mechanisms. The applicant will have open access to state-of-the-art equipment and outstanding core facilities (imaging, flowcytometry, microarrays, mass spectrometry, mouse genetics, protein expression, and crystalography). Opportunities exist for interactions with expanding clinical research programs. Excellent laboratory space, start up funds, salary and benefits will be provided. The time before tenure review will be dependent on qualifications but will not exceed 6 years. For additional information about this position, contact Dr. John A. Cidlowski, Chief, Laboratory of Signal Transduction (cidlows1@niehs. nih.gov). Highly qualified applicants should send their curriculum vita, with a one page statement of research plan and arrange for three letters of recommendation to be sent to the following address by December 31,2005. Applications received after December 31, 2005, will be considered as needed until the position is filled. Ms. Lisa Rogers (DIR05-11), National Institutes of Health, National Institute of Environmental Health Sciences, P.O. Box 12233, Maildrop A2-06, 111 Alexander Drive, Room A208, Research Triangle Park, NC 27709, e-mail: dir-appls@niehs.nih.gov 